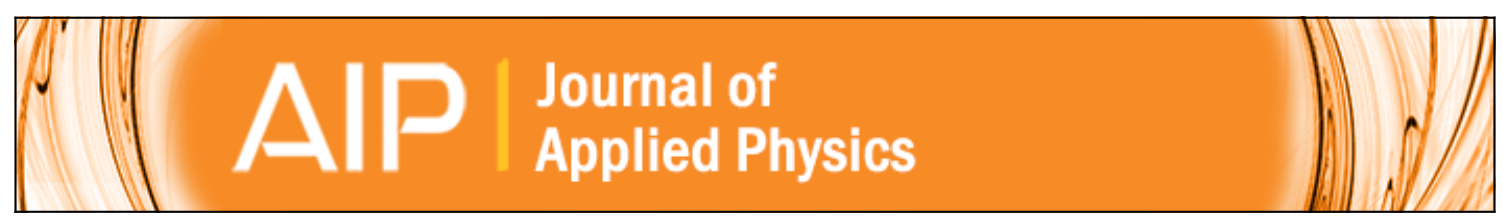

\title{
Electrical activation of boron coimplanted with carbon in a silicon substrate
}

J. P. de Souza and H. Boudinov

Citation: Journal of Applied Physics 74, 6599 (1993); doi: 10.1063/1.355098

View online: http://dx.doi.org/10.1063/1.355098

View Table of Contents: http://scitation.aip.org/content/aip/journal/jap/74/11?ver=pdfcov

Published by the AIP Publishing

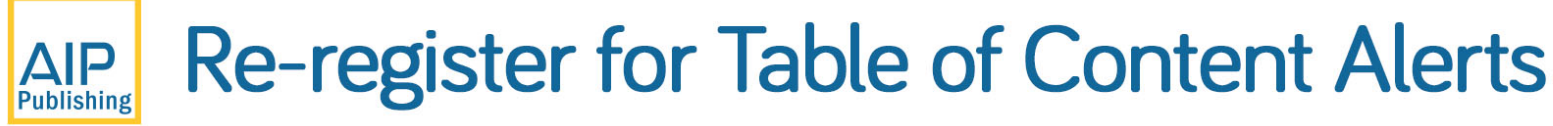

Create a profile.

Sign up today! 


\title{
Electrical activation of boron coimplanted with carbon in a silicon substrate
}

\author{
J. P. de Souza and H. Boudinov \\ Instituto de Física, UFRGS, $91501-970$ Porto Alegre, R.S., Brazil
}

(Received 28 June 1993; accepted for publication 23 August 1993)

\begin{abstract}
It is demonstrated that the electrical activation in $\mathrm{B}^{+}\left(5.0 \times 10^{14} \mathrm{~cm}^{-2}\right.$ at $\left.50 \mathrm{keV}\right)$ implanted $\mathrm{Si}$ samples submitted to furnace annealing can be noticeably affected by a $\mathrm{C}^{+}$coimplantation. It was found that a $\mathrm{C}^{+}$dose ten times lower than that of $\mathrm{B}^{+}$is not sufficient to influence the activation behavior of $\mathrm{B}$. However, $\mathrm{C}^{+}$implanted to a dose equal to or ten times higher than the $\mathrm{B}^{+}$dose contributed, respectively, to the reduction or enhancement of the electrical activation of $B$ after annealing in the temperature range of $450-700^{\circ} \mathrm{C}$. In addition, the reverse annealing of $\mathrm{B}$ is attenuated in the coimplanted samples and suppressed in samples where the $\mathrm{C}^{+}$ implantation damage was annealed prior to the $\mathrm{B}^{+}$implantation. At temperatures $>700{ }^{\circ} \mathrm{C}$ the electrical activation is not significantly affected by the $\mathrm{C}^{+}$coimplantation. A model considering interaction between $\mathrm{C}$ and $\mathrm{Si}$ self-interstitial atoms during thermal annealing is proposed to account for the activation behavior of $B$ in the dually implanted samples.
\end{abstract}

\section{INTRODUCTION}

The electrical activation behavior of $\mathbf{B}$ implanted at room temperature in a $\mathrm{Si}$ substrate presents interesting features. ${ }^{1-4}$ When $B^{+}$is implanted at doses lower than $<3 \times 10^{13} \mathrm{~cm}^{-2}$ the sheet carrier concentration increases monotonically with the increasing of the annealing temperature. However, when the $\mathrm{B}^{+}$dose exceeds $3 \times 10^{13} \mathrm{~cm}^{-2}$, reverse annealing (decreasing of the sheet carrier concentration with the increasing of the annealing temperature) takes place in the temperature range of $500-650^{\circ} \mathrm{C}$. The mechanisms for the reverse annealing are not fully established at present. North and Gibson ${ }^{2}$ suggested that interstitial $\mathrm{Si}$ atoms released from defect aggregates during annealing replace substitutional $\mathbf{B}$ atoms to interstitial sites and render them electrically inactive. Blamires ${ }^{3}$ proposed that the reverse annealing is a consequence of substitutional-interstitial $B$ pairing. Gibbons ${ }^{4}$ explained the reverse annealing assuming $B$ segregation to dislocation lines and loops to relieve the strain energy associated with the large covalent radius mismatch between substitutional $\mathrm{B}$ and Si atoms ( $\cong 25 \%$ mismatch). Huang and Jaccodine ${ }^{5}$ demonstrated that the reverse annealing is present similarly both in float zone (FZ) and in Czochralski grown (CZ) Si. Since FZ Si has low oxygen concentration, the findings of Huang and Jaccodine apparently disagree with the model proposed by Gregorkiewicz. and Ammerlaan, ${ }^{6}$ which suggests that oxygen and oxygen-related complexes may be involved in reverse annealing. Huang and Jaccodine $e^{5}$ further noticed that the reverse annealing phenomenon is absent in the $\mathrm{B}^{+}$implanted Si that underwent rapid thermal annealing (RTA). Based on the observed enhanced electrical activation of B after RTA, the authors suggested that the formation of B-point defect complexes should be the main cause for the reverse annealing because it can be affected efficiently by the heating rate.

$\mathrm{C}$ is an isoelectronic element in the Si substrate. It is normally incorporated during $\mathrm{CZ}$ or $\mathrm{FZ}$ crystal growth in concentrations, respectively, of $1-8$ and $0.1-5$ ppma. Sev- eral phenomena that take place during thermal treatments of Si wafers have been found to be influenced by the presence of $\mathrm{C}$. For example, $\mathrm{C}$ is known to affect the oxygen precipitation, ${ }^{7}$ the formation of the new donors ${ }^{8}$ in $\mathrm{CZ}$ crystals, and it is claimed to be associated with the generation of B-type defects in as-grown $\mathrm{Si}$ wafers. ${ }^{9}$ Wong et al. ${ }^{10}$ demonstrated that $\mathrm{Au}$ contamination can be gettered in a layer implanted with $\mathrm{C}^{+}$. They proposed that the gettering action is a consequence of the capturing of $\mathrm{Si}$ self-interstitials by the $\mathrm{C}$ atoms. Liefting et $a l .{ }^{11}$ showed (i) that the annealing of a $\mathrm{C}$ implantation does not result in dislocation generation even for a $\mathrm{C}^{+}$dose above 100 times that required for $\mathrm{B}^{+}$and (ii) that $\mathrm{C}$ can prevent dislocation formation of coimplanted $B$ ions. Recently, Nishikawa et al. ${ }^{12}$ demonstrated that the transient enhanced diffusion of $\mathrm{B}$ can be reduced by $\mathrm{C}$ coimplantation. Furthermore, the formation of the end of range dislocation band during the solid phase epitaxial regrowth of amorphized Si can be eliminated by a $\mathrm{C}^{+}$coimplantation. ${ }^{13}$

The above-mentioned publications strongly suggest that $\mathrm{C}$ interacts with point defects during thermal annealing. Since the electrical activation also depends on interactions between dopant atoms and point defects it may be influenced by a $\mathrm{C}^{+}$implantation. This statement is verified in the present publication comparing the activation in $\mathrm{Si}$ samples singly $\left(\mathrm{B}^{+}\right)$and dually implanted $\left(\mathrm{B}^{+}+\mathrm{C}^{+}\right)$.

\section{EXPERIMENTAL DETAILS}

Van der Pauw devices ${ }^{15}$ were fabricated using $n$-type, 4-11 $\Omega \mathrm{cm}$ resistivity (100) Si substrates. The central area of the devices was implanted with ${ }^{11} \mathrm{~B}^{+}$to the dose of $5 \times 10^{14} \mathrm{~cm}^{-2}$ at $50 \mathrm{keV}$ (control samples) or with the same $\mathrm{B}^{+}$implantation followed by ${ }^{12} \mathrm{C}^{+}$implantation to the dose of $5.0 \times 10^{13}$ (samples I), $5.0 \times 10^{14}$ (samples II), or $5.0 \times 10^{15} \mathrm{~cm}^{-2}$ (samples III) at $55 \mathrm{keV}$. The energy of the $\mathrm{C}^{+}$implantation was selected to superimpose spatially the $\mathbf{B}$ and $\mathbf{C}$ profiles. In a set of samples (samples IV) $\mathrm{C}^{+}$ was implanted to a dose of $5 \times 10^{15} \mathrm{~cm}^{-2}$ and annealed at 


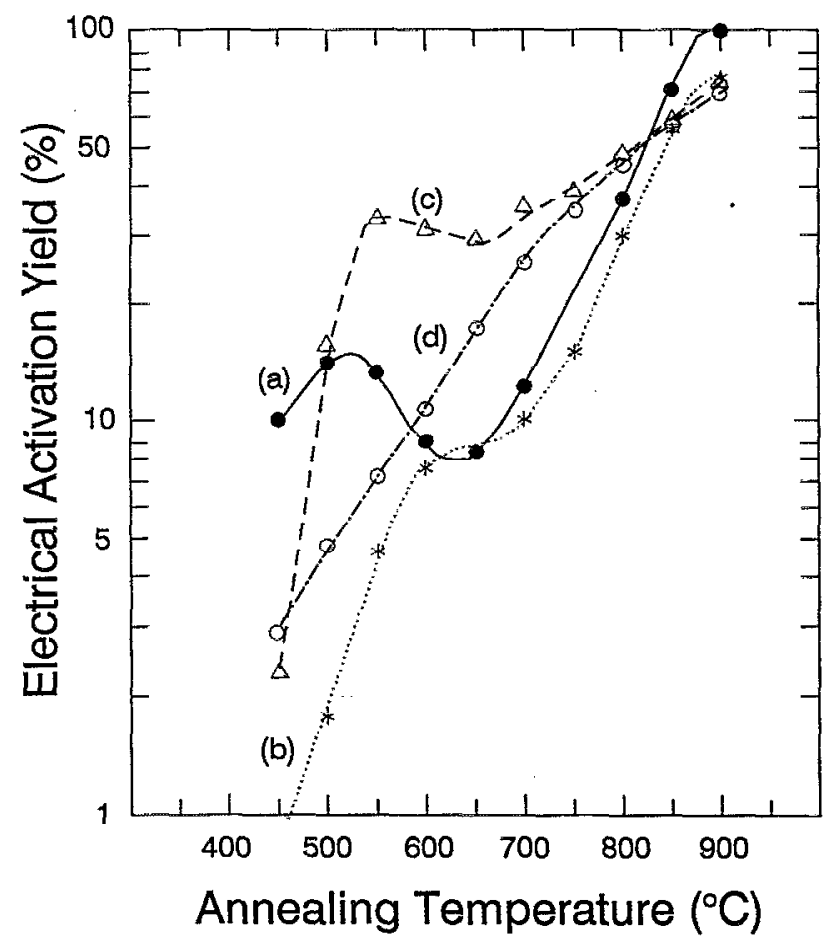

FIG. 1. Electrical activation yield after isochronal annealing for $30 \mathrm{~min}$ of samples implanted only with $\mathrm{B}^{+}\left(5.0 \times 10^{14} \mathrm{~cm}^{-2}\right.$ at $\left.50 \mathrm{keV}\right)$ [control samples, curve (a)] or dually implanted with $\mathrm{B}^{+}\left(5.0 \times 10^{14} \mathrm{~cm}^{-2}\right.$ at 50 $\mathrm{keV}$ ) and $\mathrm{C}^{+}$to the dose of $5.0 \times 10^{13} \mathrm{~cm}^{-2}$ [samples $\mathrm{I}$, curve (a)], $5.0 \times 10^{14} \mathrm{~cm}^{-2}$ [samples II, curve (b)] or $5.0 \times 10^{15} \mathrm{~cm}^{-2}$ [samples III, curve (c)]. Curve (d) shows the electrical activation yield of samples IV that were implanted with $\mathrm{C}^{+}$to a dose of $5.0 \times 10^{15} \mathrm{~cm}^{-2}$ and annealed at $900^{\circ} \mathrm{C}$ for 30 min prior to the $\mathrm{B}^{+}$implantation. All the $\mathrm{C}^{+}$implantations were performed at the energy of $55 \mathrm{keV}$.

$900^{\circ} \mathrm{C}$ for $30 \mathrm{~min}$ prior to $\mathrm{B}^{+}$implantation. Subsequently, both the singly and dually implanted samples were annealed for $30 \mathrm{~min}$ in the temperature range of $450-900^{\circ} \mathrm{C}$ in nitrogen atmosphere. The Van der Pauw devices were electrically characterized by sheet resistivity and Hall measurements.

\section{RESULTS}

Figure 1 shows the effect of the coimplanted $\mathrm{C}^{+}$dose on the electrical activation yield (EAY) of B. The EAY is considered hereafter as the ratio between sheet carrier concentration obtained from the sheet resistivity and Hall measurements and the implanted dose. Identical EAY was measured in the control and in the samples I proving that no electrical effects were introduced by the $\mathrm{C}^{+}$coimplantation at the lowest dose. As expected, the reverse annealing is clearly depicted in the temperature range of 500$650^{\circ} \mathrm{C}$. When equal $\mathrm{C}^{+}$and $\mathrm{B}^{+}$doses are implanted (samples II) the EAY of B is noticeably reduced at temperatures $\angle 550^{\circ} \mathrm{C}$ [compare curve (b) with curve (a) in Fig. 1]. However, the EAY of samples II is close to that of control samples for temperatures $>600^{\circ} \mathrm{C}$. In each of these two temperature regions the EAY increases linearly with the increasing of the annealing temperature in the log-linear plot of Fig. 1. The reverse annealing does not appear clearly in samples II since only a vestige can be denoted by the saddle point in curve (b) of Fig. 1 at a temperature of $\approx 650^{\circ} \mathrm{C}$.

The coimplantation of $\mathrm{C}^{+}$with a dose ten times higher than that of $\mathrm{B}^{+}$(samples III) resulted in a steep increase of the activation of $B$ with the increasing of the annealing temperature in the range of $400-500^{\circ} \mathrm{C}$ [see curve (c) in Fig. 1]. The EAY of $B$ in the temperature range of 500$850^{\circ} \mathrm{C}$ is significantly enhanced by the $\mathrm{C}^{+}$coimplantation [compare curve (c) with curve (a) in Fig. 1]. A maximum enhancement factor of $\cong 4$ times occurred after an annealing of $650^{\circ} \mathrm{C}$. The reverse annealing is clearly seen in the activation behavior of samples III as depicted in curve (c) of Fig. 1. However, the deactivated maximum fraction of the implanted dose by virtue of the reverse annealing in samples III (4\%) is lesser than in the control samples (7\%). At temperatures higher than $850^{\circ} \mathrm{C}$ the EAY in samples III becomes somewhat inferior to that of control samples.

The annealing of the $\mathrm{C}^{+}$implantation prior to the $\mathrm{B}^{+}$ implantation (samples IV) caused noticeable changes in the activation behavior of $B$. The EAY in samples IV increases monotonically with the increasing of annealing temperature and no evidence of reverse annealing is observed. It can be fitted by two straight lines in the log-linear graph of Fig. 1, intersecting at a temperature of $\approx 700{ }^{\circ} \mathrm{C}$.

\section{DISCUSSIONS AND CONCLUSIONS}

The presented results demonstrated that besides the isoelectronic characteristics of $\mathrm{C}$ in the $\mathrm{Si}$ substrate the implantation of this element can strongly affect the activation behavior of coimplanted $\mathbf{B}^{+}$. There are two main components associated with the $\mathrm{C}^{+}$implantation that influence the activation of $\mathrm{B}:(\mathrm{i})$ the associated implantation damage and (ii) the $\mathrm{C}$ concentration level in the $\mathrm{B}$ doped layer. In the case of the lowest $\mathrm{C}^{+}$dose (samples $\mathrm{I}$ ) both the implantation damage and $\mathrm{C}$ concentration $(0.1$ times the $\mathrm{B}$ concentration) were below the minimum level to noticeably affect the activation of $\mathrm{B}$. For the case of equal $\mathrm{B}^{+}$and $\mathrm{C}^{+}$doses it seems that the $\mathrm{C}$ doping should be the most relevant factor for the changes in the activation of $B$. Aligned Rutherford backscattering analysis taken subsequently to the implantation revealed an unexpected lower damage concentration in samples II than in the control samples. This seems to indicate that partial annealing of the $\mathrm{B}^{+}$implantation damage occurred during the subsequent $\mathrm{C}^{+}$bombardment. The causes for this annealing are presently unknown.

The effect of the implantation damage on the EAY of $B$ was investigated in a separate experiment where an inert element ion $\left({ }^{20} \mathrm{Ne}^{+}\right)$replaced the $\mathrm{C}^{+}$coimplantation. The $\mathrm{Ne}^{+}$implantation energy of $90 \mathrm{keV}$ was determined ${ }^{15}$ to obtain a maximum of nuclear energy deposition at the depth corresponding to the projected range of the $\mathrm{B}^{+} \mathrm{im}$ plantation. A Ne+ dose $1.0 \times 10^{14} \mathrm{~cm}^{-2}$ was chosen in order to prevent amorphization of Si. The EAY of the $\mathrm{Ne}^{+}$ coimplanted samples together with that of the control samples are shown in curves (b) and (a) of Fig. 2, respectively. It is clearly seen [curve (b)] that the additional 


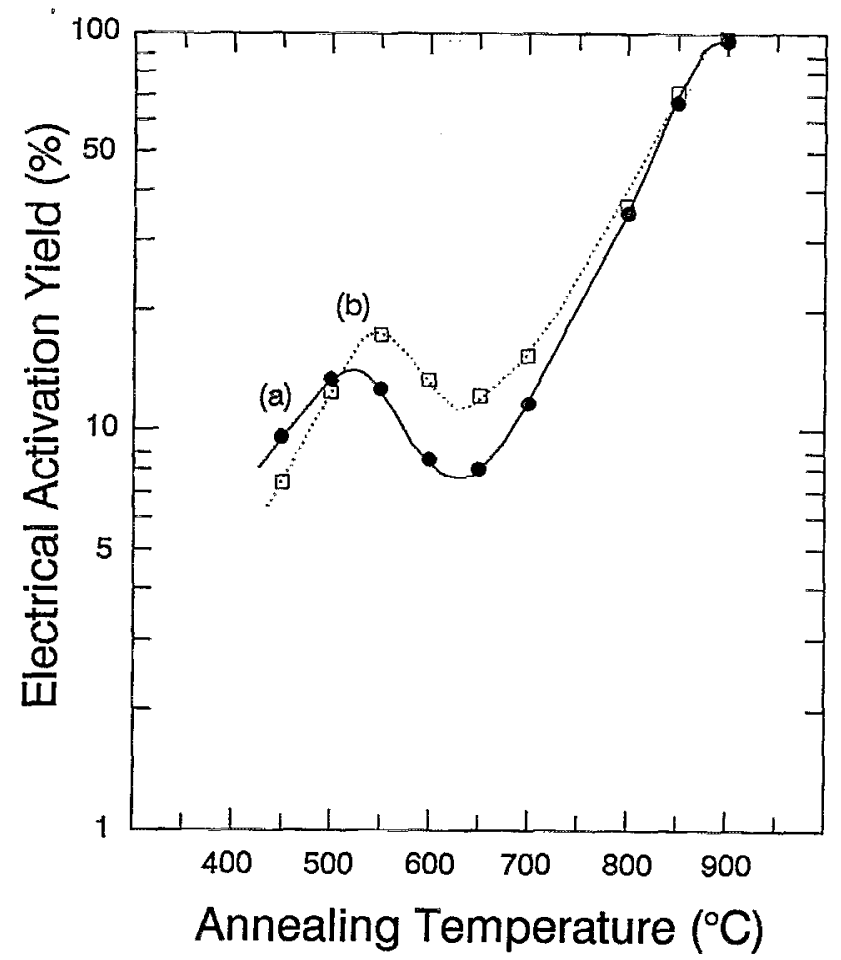

FIG. 2. Electrical activation yield after isochronal annealing for $30 \mathrm{~min}$ of samples implanted only with $\mathrm{B}^{+}\left(5.0 \times 10^{14} \mathrm{~cm}^{-2}\right.$ at $\left.50 \mathrm{keV}\right)$ [curve (a)] or dually implanted with $\mathrm{B}^{+}\left(5.0 \times 10^{14} \mathrm{~cm}^{-2}\right.$ at $\left.50 \mathrm{keV}\right)$ and $\mathrm{Ne}^{+}$ $\left(1.0 \times 10^{14} \mathrm{~cm}^{-2}\right.$ at $\left.90 \mathrm{keV}\right)$ [curve (b)].

damage introduced by the $\mathrm{Ne}^{+}$bombardment correlates with the improvement of the electrical activation of $B$ at $T>500^{\circ} \mathrm{C}$. One may notice that independently of the different damage concentration level in the two sets of samples a reverse annealing with similar magnitude is observed.

When $\mathrm{C}^{+}$is coimplanted to a heavy dose (ten times the $\mathrm{B}^{+}$dose) both the implantation damage and $\mathrm{C}$ concentration level seem to influence the activation of $\mathrm{B}$. The activation enhancement at the temperature range of 500 $850^{\circ} \mathrm{C}$ is probably related to the implantation damage introduced by the high $\mathrm{C}^{+}$dose. On the other hand, the "softening" of the reverse annealing should be related to the high $\mathrm{C}$ concentration level. When the implantation damage of the $\mathrm{C}^{+}$implantation is annealed prior to the $\mathrm{B}^{+}$ implantation, the major role in the activation behavior of $B$ should be played by the $\mathrm{C}$ doping level. Then, the most prominent result is the complete suppression of the reverse annealing.

In order to interpret the above results we proposed the following model. The as-implanted $B$ atoms are located at substitutional lattice sites ${ }^{2}$ and at non substitutional positions surrounded by the implantation damage. ${ }^{2}$ In any of these cases, the as-implanted $B$ atoms do not contribute to $p$-type doping. The substitutional B may be associated with point defects, probably vacancy or vacancy complexes. The heating of $\mathrm{B}^{+}$implanted samples results in the onset of defect annealing and dissociation of the B-point defect complexes and hence of the electrical activation. Simultaneously with the increasing of the annealing temperature, the initial fraction of substitutional $\mathbf{B}$ decreases, reaching a minimum value at $650{ }^{\circ} \mathrm{C}^{2}$ Probably, during annealing of coimplanted samples, self-interstitial $\mathrm{Si}$ atoms $\left(\mathrm{Si}_{I}\right)$ are gettered by the $\mathrm{C}$ atoms. As a consequence of the decreasing of the $\mathrm{Si}_{I}$ concentration, the dissociation rate of B-vacancy complexes via interaction with $\mathrm{Si}_{I}$ should decrease. This is in agreement with the observed reduction of EAY in samples coimplanted with $\mathrm{C}^{+}$having a low damage concentration level (samples II and IV). Considering the reverse annealing as caused primarily by the interaction between substitutional $\mathrm{B}$ and $\mathrm{Si}_{I}$ atoms, the gettering of $\mathrm{Si}_{I}$ by the $\mathrm{C}$ atoms results in a lower deactivated dose of $B$ in the temperature range of $500-650^{\circ} \mathrm{C}$ in the coimplanted samples (samples II and III) compared to that in the control samples. By similar arguments, one can expect that the reverse annealing may be suppressed in samples having both high $\mathrm{C}$ concentration and low damage concentration (samples IV). The effect of the implantation damage on the activation of $\mathrm{B}$ can be explained considering that the $\mathrm{Si}_{I}$ concentration should increase with the increase of implantation damage for ion doses below the amorphization threshold. ${ }^{16}$ Consequently, the dissociation of B-vacancy complexes should occur at a rate that increases with the increasing of the damage concentration. This accounts for the enhanced activation in sample coimplanted with $\mathrm{Ne}^{+}$or with $\mathrm{C}^{+}$(samples III).

In summary, the electrical activation of $B$ in samples coimplanted with $\mathrm{C}^{+}$at doses lower, equal to, or higher than that of $\mathrm{B}^{+}$is discussed. It was found that both the implantation damage and the $\mathrm{C}$ concentration influence significantly the electrical activation behavior of $B$. The influence of the crystal damage on the activation of $B$ was demonstrated by the enhanced activation in samples coimplanted with $\mathrm{Ne}^{+}$. The effect of the $\mathrm{C}$ doping level on the activation behavior of $\mathrm{B}$ was established by the lack of reverse annealing in samples where the $\mathrm{C}^{+}$implantation damage was annealed prior to the $\mathrm{B}^{+}$implantation. $\mathrm{A}$ model suggesting a competition between the capture of $\mathrm{Si}_{I}$ by the $\mathrm{C}$ atoms and the interaction of $\mathrm{Si}_{I}$ with $\mathrm{B}$-vacancy complexes and with substitutional $\mathrm{B}$ atoms is proposed to account for the presented results.

${ }^{1}$ T. E. Seidel and A. U. MacRae, Radiat. Eff. 7, 1 (1971).

${ }^{2}$ J. C. North and W. M. Gibson, Appl. Phys. Lett. 16, 126 (1970).

${ }^{3}$ N. G. Blamires, European Conference on Ion Implantation (Peregrinus, Stevenage, England, 1970), p. 52.

${ }^{4}$ J. F. Gibbons, Proc. IEEE 60, 1062 (1972).

${ }^{5}$ J. Huang and R. J. Jaccodine, in Rapid Thermal Processing, edited by T. O. Sedgwick, T. E. Seidel, and B.-Y. Tsaur (Materials Research Society, Pittsburgh, 1986), Vol. 52, p. 57.

${ }^{6}$ T. Gregorkiewicz and C. A. J. Ammerlaan, Radiat. Eff. Lett. 85, 249 (1985).

${ }^{7} \mathrm{~J}$. Wang and M. Kulkarni, presented at ECS-Meeting, Ext. Abstr. No. 532, FL (1980).

${ }^{8}$ A. Kanamori and M. Kanamori, J. Appl. Phys. 50, 8095 (1979).

${ }^{9}$ J. Chikawa and S. Shirai, J. Cryst. Growth 39, 4 (1976).

${ }^{10}$ H. Wong, N. W. Cheung, K. M. Yu, P. K. Chu, and J. Liu, in Ion Beam Processing of Advanced Electronic Materials, edited by N. W. Cheung, A. D. Marwick, and J. B. Roberto (Materials Research Society, Pittsburgh, 1989), Vol. 147, p. 97.

${ }^{11}$ J. R. Licfting, J. S. Custer, and F. W. Saris, in Phase Formation and Modification by Beam-Solid Interactions, edited by G. S. Was, L. E. 
Rehn, and D. M. Follstaedt (Materials Research Society, Pittsburgh, 1992), Vol. 235, p. 179.

${ }^{12}$ S. Nishikawa, A. Tanaka, and T. Yamaji, Appl. Phys. Lett. 60, 2270 (1992).

${ }^{13}$ S. Nishikawa and T. Yamaji, Appl. Phys. Lett. 62, 303 (1993).
${ }^{14}$ L. J. Van der Pauw, Philips Res. Rep. 13, 1 (1958).

${ }^{15} \mathrm{~J}$. F. Ziegler, J. P. Biersack, and U. Littmark, in The Stopping and Ranges of Ions in Solids (Pergamon, New York, 1985).

${ }^{16}$ R. J. Schreutelkamp, J. S. Custer, J. R. Liefting, W. X. Lu, and F. W. Saris, Mater. Sci. Rep. 6, 275 (1991). 